\title{
Heat treatment of composite based on MAX-phases of the Ti-Al-C system
}

\author{
Sergey Galyshev ${ }^{1, *}$, Pavel Bazhin ${ }^{2}$, Alexander Stolin ${ }^{2}$, Fanil Musin ${ }^{1}$, and Vasiliy Astanin ${ }^{1}$ \\ ${ }^{1}$ Ufa State Aviation Technical University, 450000 Ufa, Russia \\ ${ }^{2}$ Russian Academy of Sciences Institute of Structural Macrokinetics and Materials Science RAS, 142432 Chernogolovka, Russia
}

\begin{abstract}
This paper studies the effect of heat treatment performed at the MAX-phases formation temperature on the phase composition of the MAX/TiC-composite formed in the $\mathrm{Ti}-\mathrm{Al}-\mathrm{C}$ system in the conditions of free SHS-compression. The dependence between the titanium carbide (TiC) content and delay time before applying the load during free SHS-compression is defined. The experimental results show that the proposed heat treatment leads to carbide content reduction.
\end{abstract}

\section{Introduction}

In recent years MAX-phase materials have been increasingly used in industry due to their unique properties. The crystalline lattice of MAX-phases $\left(\mathrm{M}_{\mathrm{n}+1} \mathrm{AX}_{\mathrm{n}}\right)$ is an alternation of intermetallic "MA" and carbide or nitride "MX" layers, where " $\mathrm{M}$ " is a transition metal; "A" is a IIIA or IVA group element, " $\mathrm{X}$ " is either $\mathrm{C}$ or $\mathrm{N}$. This structure of MAX-phases determines a combination of useful metallic and ceramic properties in one material.

Due to the structure of MAX-phases, MAX-phase materials satisfy the highest requirements associated with high temperatures, corrosion environment and thermal cycling [1-4]. For the same reason, these materials can be used in various advanced industries, such as aircraft and aerospace engine building, electrochemical and electrical industries.

The properties of MAX-phase materials vary in a wide range depending on the phase composition. For example, $\mathrm{TiC}$ is exceptionally undesirable for high-temperature application of MAX-phase materials based on the Ti-Al$\mathrm{C}$ system. This is connected with a large difference in the thermal expansion coefficients of the carbide and MAX phases, which results in high temperature embrittlement of the material due to the carbide phase. On the other hand, TiC significantly increases the wear resistance of material. It is important for application in areas that do not require high-temperature properties, for example as coatings for electrical contacts [5].

In case of the latter, one can speak of a dispersion hardened composite, in which the MAX phases are the matrix material, and the carbide precipitates function as a reinforcing component. The change in the carbide phase volume makes it possible to control the performance properties of the MAX/TiC-composite. Therefore, the search for this possibility is of indisputable practical interest.
To date, methods of powder metallurgy are the most widely used ones for producing materials based on MAXphases [6]. These methods have some disadvantages such as large time and energy costs, many technological stages, etc. The techniques based on SHS-technology (selfpropagating high-temperature synthesis) seem more promising for production of MAX-phase materials, as SHS allows fabricating refractory compounds with minimal energy consumption in the shortest time [7]. This means that the SHS-technology is more customeroriented, which in its turn is an important economical feature of composite materials technology.

Phase formation in the Ti-Al-C system during SHS occurs at high rate and high temperature of the combustion reaction. This determines some difference from the process of equilibrium crystallization of these compounds. First, TiC forms as a result of reaction between $\mathrm{Ti}$ and $\mathrm{C}$. At the same time, due to high reaction exothermicity of $\mathrm{TiC}$ formation, $\mathrm{Al}$ and remaining Ti melt and form the Ti-Al melt. Further, the Ti-Al melt interacts with the carbon surface. As a result the melt picks up carbon, and secondary $\mathrm{TiC}$ grains precipitate from the melt. MAX-phases Tix $+1 \mathrm{AlCx}$ form from the melt, as well as during the interaction of the melt with $\mathrm{TiC}$ [9]. If the subsequent cooling occurs at rather high rates, the TiC cannot completely interact with the Ti-Al melt. The TiC remains in the volume of the synthesized material, and the MAX/TiC-composite forms.

The study of the equilibrium process of Ti-Al-C compound formation using the differential-thermal analysis during slow heating in the temperature range from 25 to $1400{ }^{\circ} \mathrm{C}$ revealed two stages [8]. At the first stage $\mathrm{Ti}_{\mathrm{x}} \mathrm{Al}_{\mathrm{y}}$ type intermetallic compounds form by the reaction:

$$
\mathrm{xTi}+\mathrm{yAl} \rightarrow \mathrm{Ti}_{\mathrm{x}} \mathrm{Al}_{\mathrm{y}}
$$

\footnotetext{
"Corresponding author: galyshew@gmail.com
} 
During the second stage, $\mathrm{TiC}$ forms, then it reacts with intermetallic compounds and aluminum melt to form MAX-phases $\mathrm{Ti}_{\mathrm{x}+1} \mathrm{AlC}_{\mathrm{x}}$ by the following reactions:

$$
\begin{aligned}
& \mathrm{TiC}+\mathrm{Ti}_{\mathrm{x}} \mathrm{Al}_{\mathrm{y}} \rightarrow \mathrm{Ti}_{\mathrm{x}+1} \mathrm{AlC}_{\mathrm{x}} ; \\
& \mathrm{TiC}+\mathrm{Al} \rightarrow \mathrm{Ti}_{\mathrm{x}+1} \mathrm{AlC}_{\mathrm{x}} .
\end{aligned}
$$

Thus, one can assume that the $\mathrm{TiC}$ content in the TiAl-C-based composite can be controlled in two ways. First, if it is necessary to increase the TiC content, one should increase the cooling rate immediately after the synthesis. On the other hand, the cooling rate should be reduced if its fraction in the material is required to be decreased.

For example, it was shown in [9] that spontaneous air cooling of samples with the tool immediately after the free SHS-compression resulted in formation of composite with $20 \%$ TiC.

Another way to reduce the $\mathrm{TiC}$ content in the material is apparently heat treatment at a temperature close to the temperature of MAX-phase formation by reactions (2) and (3). However, this issue has not been studied in full and requires additional research.

The aim of this work is to determine the effect of hightemperature annealing on the $\mathrm{TiC}$ content in the MAX/TiC composite produced by free SHScompression.

\section{Materials and procedures}

Powders of titanium (PTM), aluminium (ASD-4) and carbon black were used as initial materials. The powder mixture composition corresponded to the stoichiometric composition of the MAX phase of Ti2AlC. The initial cylindrical samples are $30 \mathrm{~mm}$ high and $30 \mathrm{~mm}$ in diameter, the relative density is $60 \%$.

The free SHS-compression [10] is used to prepare samples of the MAX/TiC-composite material. This method consists in free compression of the synthesized material immediately after the synthesis (Fig. 1).

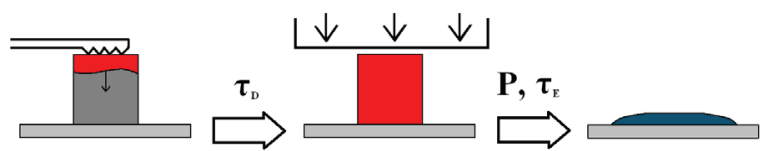

Fig. 1. Scheme of free SHS-compression

The time between the synthesis end and deformation start (delay time) is the main technological parameter, which determines the structure and properties of the produced material. The parameter varies from 0 to 10 seconds with a step of 2 seconds. The compression load is constant of $15 \mathrm{MPa}$.

Two series of samples are produced at different delay times. Then, one of the sample series is annealed at $1350^{\circ} \mathrm{C}$ in the air atmosphere for 3 hours and after cooled in water.

Both series of samples are cut, grinded and polished without etching. The microstructure before (PS - parent sample) and after annealing (HT_1350 - heat treatment $1350^{\circ} \mathrm{C}$ ) is analyzed by means of a scanning electron microscope LEO-1450 with an energy-dispersive microanalyzer INCA Energy (EDS system). X-ray phase analysis is carried out on a DRON-3 (LOMO) equipment, using a copper anti-cathode X-ray tube at $40 \mathrm{kV}$ of accelerating voltage and $30 \mathrm{~mA}$ of heating current. The microhardness of the samples is measured by the Vickers method, using a Duramin-2 equipment.

\section{Results and discussion}

The samples before annealing have a structure typical of materials based on MAX-phases of the Ti-Al-C system produced by the free SHS-compression method (Fig. 2). Light rounded inclusions of $\mathrm{TiC}$ particles in the composition with darker elongated grains of MAX phases are located in the intermetallic matrix of Ti-Al. The areas of black colour are pores.

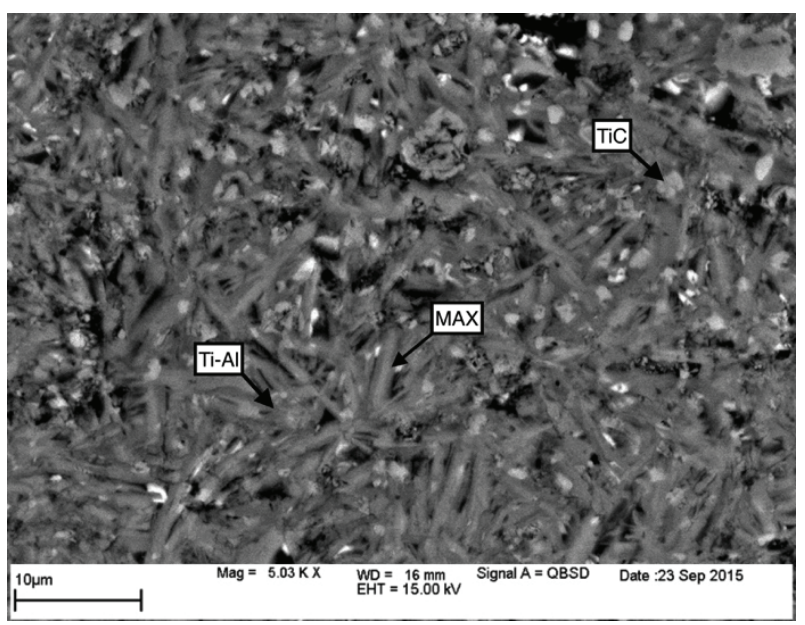

Fig. 2. Microstructure of samples obtained with a 4 seconds delay time in the initial state

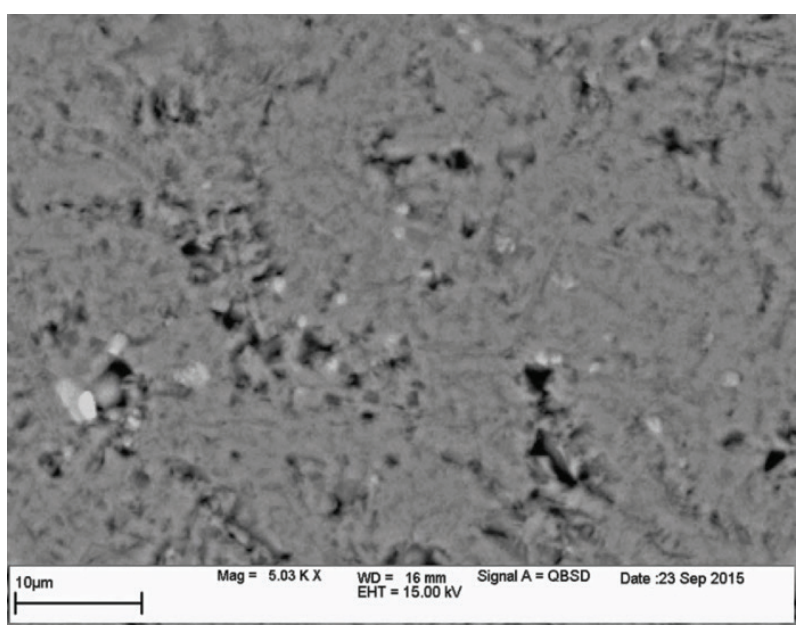

Fig. 3. Microstructure of samples obtained with a 4 seconds delay time after annealing

The metallographic analysis shows that the TiC content reduces from $27 \%$ to $11 \%$ when the delay time increases from 0 to 10 seconds (Fig. 4) Consequently, the phase formation process proceeds more completely with 
a longer dwelling at a high temperature close to the synthesis temperature.

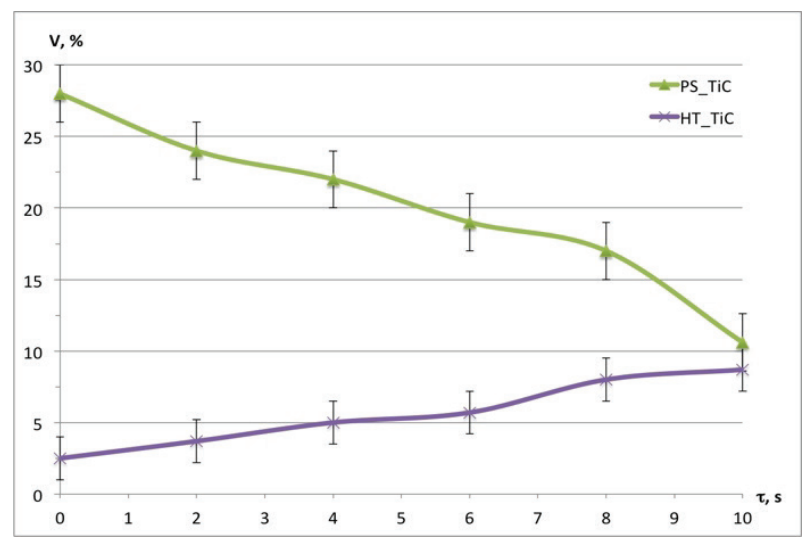

Fig. 4. Dependence of the TiC volume fraction on the delay time in the initial and annealed states

The TiC content significantly reduces when annealed at $1350^{\circ} \mathrm{C}$ (Fig. 4). The change in the $\mathrm{TiC}$ content obviously depends on the delay time, during which the material is produced. The content of $\mathrm{TiC}$ is maximally reduced in the samples produced without delay in time.

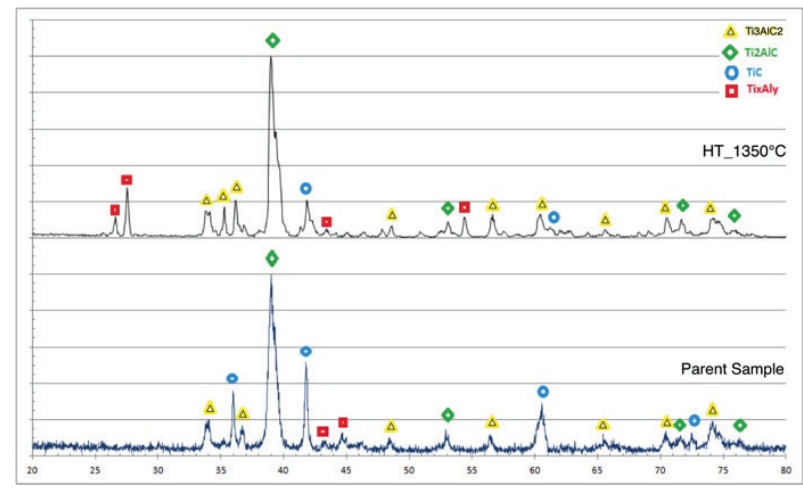

Fig. 5. X-ray diffraction spectrum of samples produced with a 6 seconds delay in the initial and annealed states

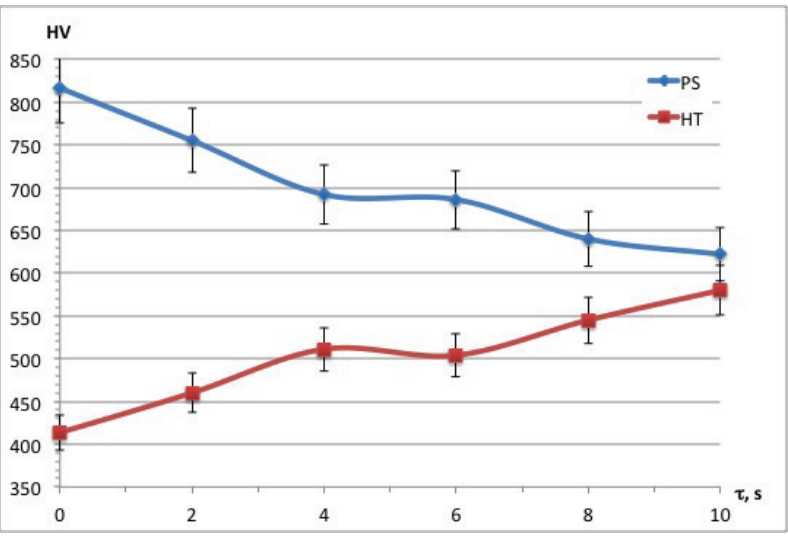

Fig. 6. Dependence of the composite microhardness on the delay time in the initial and annealed states

The TiC content reduction is confirmed by the X-ray spectra. The intensity of $\mathrm{TiC}$ peaks after annealing decreases (Fig. 5).

The obtained data correlate well with the microhardness measurements (Fig. 6). The material microhardness is determined by the content of the hardest phase - TiC $(\mathrm{HV}=30 \mathrm{GPa})$. Samples with a high TiC content have a higher microhardness. On the other hand, the microhardness of the sample with the minimum carbide content produced is close to the microhardness of pure MAX-phases $\left(\mathrm{HV}_{\mathrm{Ti} 3 \mathrm{AlC} 2}=4.9 \mathrm{GPa}, \mathrm{HV}_{\mathrm{Ti} 2 \mathrm{AlC}}=4.5\right.$ $\mathrm{GPa})$.

\section{Conclusions}

1. The dependence between the parameters of the $\mathrm{MAX} / \mathrm{TiC}$ composite structure and the delay time prior to load application during the free SHS compression is established. The TiC content reduced from $27 \%$ to $11 \%$ when the delay time increased from 0 to 10 seconds.

2. The method to control the MAX/TiC-composite structure by high temperature annealing is shown. This heat treatment provides a decrease in the TiC content. The range of possible $\mathrm{TiC}$ content in the composite is from 3 to $27 \%$.

This work has been performed with the financial support of the Ministry of Education and Science of the Russian Federation within the framework of the base part of the state task №11.6454.2017/BP.

\section{References}

1. R. Tomoshige, H. Tanaka, Arch. Metall. Mater. 59, 1575 (2014)

2. T.A. Prikhna, S.N. Dub, A.V. Starostina, J. superhard mater. 34, 102 (2012)

3. A.V. Starostina, T.A. Prikhna, M.V. Karpets, J. superhard mater. 33, 307 (2011)

4. M.W. Barsoum, MAX Phases: Properties of Machinable Carbides and Nitrides (Wiley VCH, 2013)

5. A. Rahman, Z. Rahaman, AJMP 4, 75 (2015)

6. M.W. Barsoum, T. El-Raghy, Am. Sci. 89, 334 (2001)

7. A.G. Merzhanov, J. Mater. Chem. 14, 1779 (2004)

8. E.A. Levashov, Yu.S. Pogozhev, D.V. Shtansky, M.I. Petrzhik, Izvestiya VUZ. PMFP (In Rissian) 3, 91 (2008)

9. S.N. Galyshev, N.G. Zaripov, P. M. Bazhin, A. M. Stolin, PM (In Rissian) 11, 63 (2015)

10. S.N. Galyshev, A.M. Stolin, D. Vrel, A. Hendaoui, P.M. Bazhin, A.E. Sytschev, Int. J. SHS 18, 194 (2009) 